\title{
Defence industries and open innovation: ways to increase military capabilities of the Portuguese ground forces
}

\author{
João Reis, Nuno Melão, Joana Costa \& Bohuslav Pernica
}

To cite this article: João Reis, Nuno Melão, Joana Costa \& Bohuslav Pernica (2022): Defence industries and open innovation: ways to increase military capabilities of the Portuguese ground forces, Defence Studies, DOI: 10.1080/14702436.2022.2033117

To link to this article: https://doi.org/10.1080/14702436.2022.2033117

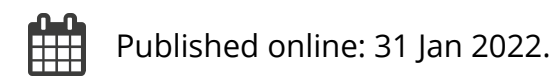

Submit your article to this journal $\left[\begin{array}{c}0 \\ 0\end{array}\right.$

\section{Џ Article views: 37}

\section{Q View related articles $\square$}

\section{View Crossmark data \lceil}




\title{
Defence industries and open innovation: ways to increase military capabilities of the Portuguese ground forces
}

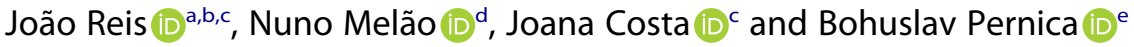 \\ alndustrial Engineering and Management, Faculty of Engineering, Lusofona University and EIGeS, Lisbon, \\ Portugal; ${ }^{b}$ Research and Development Center, Military University Institute, Lisbon, Portugal; 'Department of \\ Economics, Management, Industrial Engineering and Tourism, Govcopp, Aveiro University, Campus \\ Universitário de Santiago, Aveiro, Portugal; ${ }^{\mathrm{d}} \mathrm{CISeD}-$ Research Center in Digital Services, Polytechnic Institute \\ of Viseu, Campus Politécnico, Viseu, Portugal; eInstitute of Administrative and Social Sciences, Faculty of \\ Economics and Administration, University of Pardubice, Pardubice, Czechia
}

\begin{abstract}
The European Defence Industry is undergoing profound changes. Industrial activity is now operating on a quintuple helix innovation model with the deep involvement of universities and governments in innovation. In addition, military innovations are being transferred to civil society, with increasing attention paid to the environment. In the first stage, we report on the state-of-the-art of existing research using PRISMA protocol. The PRISMA technique is widely accepted by the academic community for its ability to discover concepts, ideas, and debates about the defence industry. In the second stage, we present a case study involving the Portuguese Defence Industry, for which multiple data collection sources were used to ensure triangulation and corroboration. The results show that, in the light of the quintuple helix innovation model, it was possible to bring applications from theoretical discussion to real life. Moreover, within the scope of the triple helix, it was possible to develop, produce and test military products, allowing to improve the military capacity of ground forces. In the future, ecological concerns will likely increase, so we suggest a greater focus on this area of research.
\end{abstract}

\section{ARTICLE HISTORY}

Received 14 January 2022

Accepted 20 January 2022

\section{KEYWORDS}

Defence industry; open innovation; ground military forces; quintuple helix

\section{Introduction}

Open Innovation (OI) is currently at the centre of academic debate. This phenomenon is identified by several scholars, who argue that it is not uncommon to find articles referring to OI and its ability to integrate internal and external knowledge in companies' value chain (Rogo et al. 2014; Brunswicker and Vanhaverbeke 2015). In this regard, Chesbrough (2003) mentioned that OI started when organisations realised they

CONTACT João Reis p40500@ulusofona.pt @ Industrial Engineering and Management, Faculty of Engineering, Lusofona University and EIGeS, Campo Grande, 1749-024 Lisbon, Portugal; Research and Development Center, Military University Institute, Rua de Pedrouços, 1449-027 Lisbon, Portugal; Department of Economics, Management, Industrial Engineering and Tourism, Govcopp, Aveiro University, Campus Universitário de Santiago, 3810-193 Aveiro, Portugal; CISeD-Research Center in Digital Services, Polytechnic Institute of Viseu, Campus Politécnico, 3504-510 Viseu, Portugal; Department of Economics, Management, Industrial Engineering and Tourism, Govcopp, Aveiro University, Campus Universitário de Santiago, 3810-193 Aveiro, Portugal; Institute of Administrative and Social Sciences, Faculty of Economics and Administration, University of Pardubice, Pardubice, Czechia 
could not solely rely on their own research and development capacities. This situation triggered the adoption of a new innovation approach focused on the collaboration with external stakeholders to share knowledge, resources, and technologies (Randhawa et al. 2016).

The scarcity of published articles on OI in the defence industry is well evidenced in the largest databases of peer-reviewed literature. To support our argument, on May $9^{\text {th }}, 2021$, we conducted a quick search on Scopus (Elsevier), which resulted in six documents with the search terms "open innovation" AND "defence industry" in the title-abstractkeywords. Thus, very few studies similar to this one have been identified. Worthy of note is the Triple Helix (TH) approach (Etzkowitz and Leydesdorff 1995, 2000) used by the Brazilian Army (Fernandes et al. 2020), which stimulated innovation between the Army, the defence industry, and the academy. Similar research was conducted in Portugal with a paper that analyses the relationship (i.e. $\mathrm{TH}$ ) within the defence industry to determine how the university-government-industry relationship works (Simões et al. 2020). The few existing studies analyse the adoption of the $\mathrm{TH}$ model and OI by the defence industry, but none have studied other recent typologies. For example, the Quadruple Helix incorporates the TH (university-industry-government) while adding the "public based on media and culture" and "civil society" (Carayannis and Campbell 2009, 2012). Moreover, the Quintuple Helix (QH) innovation model is more holistic and incorporates the "natural environments of society" (Carayannis and Campbell 2010). Our paper addresses this gap, specifically understand if the defence industry and OI allow the establishment of innovative dynamics in the light of the $\mathrm{QH}$; Within the defence industry, we focus on the Army, given the increasing military capabilities of ground forces (Fernandes et al. 2020).

To fill that gap in the literature, the objective of this research is twofold. Our first objective was to understand a phenomenon that has been little studied and for which little is known (Yin 2018); to do so, we used a Systematic Literature Review (SLR) to collect and analyse the most relevant data. The second objective was to describe the phenomenon in its natural setting; to do so, we conducted a case study research to corroborate the results from the literature and find novel insights. That said, we developed two research questions (RQ), as follows:

RQ1: How is OI improving the defence industry and increasing military capabilities?

RQ2: How is the QH innovation model dynamising the military capabilities of ground forces?

The first research question is central, as this study focuses on open innovation in defence industries. Furthermore, we identified the need to define a second research question to discuss a more focused topic and deepen the research, analysing, in that regard, the military land resources in the light of the quintuple helix. For a better understanding, we also divided this article into five sections. We started with an introduction to the topic, and in the next section, we discuss the most relevant concepts, which will be helpful for the results and discussion section. The third section presents the research design and is subdivided into two parts: the first focuses on explaining the SLR; the second focuses on the case study research. The fourth section reports the results and discussion of this research. Finally, we present the conclusions, which focus on the contributions to literature and management practice, the limitations, and perspectives for future research. 


\section{Conceptual background}

This section addresses relevant concepts, whereas the theoretical framework will be discussed in-depth in the results section.

\section{European Union (EU) defence industry}

The priority of European Defence lies in the level of evolutionary ambition through the Common Security and Defence Policy (CSDP) and at the revolutionary impulse through European Defence Funds (EDF). The CSDP enables the European Union (EU) to meet its crisis management responsibilities and act as a global security actor, taking a leading role in peacekeeping operations and conflict prevention operations (EEAS 2021a). While, the European External Action Service (EEAS) is the EU's diplomatic service that manages the EU's relations with other countries outside the bloc and conducts EU foreign and security policy (EEAS 2021b). Moreover, in the EU, the Directorate-General for Defence Industry and Space (DG DEFIS) leads the activities of the European Commission in the defence industry and space sector, being in charge of upholding the competitiveness and innovation of the European defence industry (DEFIS 2021). Some key actions and priorities of the DG DEFIS are: 1) to implement and oversight the European Defence Fund (EDF), which is one of the European Commission's main initiatives supporting research and the development of defence capabilities (for 2021-2027) (EU Space Policy); and 2) to build an open and competitive European defence equipment market and enforcing EU procurement rules on defence.

Regarding the EU defence industry, a relevant episode may be identified in mid-2004, as a defence structure was created under a Joint Action of the EU Council of Ministers, called European Defence Agency (EDA) (EDA 2021a). This agency promotes, supports, and integrates the EU member states in improving the European defence capabilities within the EU's CSDP. In 2016, the European Commission proposed the European Defence Action Plan (EDAP), intended to increase the research and development capabilities of the EU defence industry and promoting the investment in the EUs' Defence Technological and Industrial Base (EDTIB) (DGNDR 2021a). One year later, in 2017, the 25 EU Member States ratified the intention of launching a Permanent Structured Cooperation (PESCO) and, in the same year, the first research grant agreement, directly funded by the EU is signed. Moreover, the EDA and the EEAS together form the Secretariat of the PESCO, which serves as a platform and where PESCO participating Member States nations can "identify, assess and consolidate" projects to make sure they respond to the Capability Development Plan (CDP) (EDA 2021b). The CDP is produced by EDA (in cooperation with the EU Military Committee (EUMC) and the European Union Military Staff (EUMS)) to address long-term security and defence challenges, making recommendations about the EU military capabilities over time, including future scenarios (EDA 2021c). The CDP is of particular importance, as it served as a baseline for the implementation of major EU defence initiatives launched following the 2016 EU Global Strategy - as the CARD (Coordinated Annual Review on Defence), the PESCO, and the EDF. The most tangible output of the 2018 CDP revision is the eleven new EU Capability Development Priorities in fields such as cyber response operations, ground combat capabilities, air mobility, among others (EDA 2021c). 
If in one hand, it is a symbol of the EU's commitment in trying to create a solid and integrated Pan-European defence industry (European Parliament 2020); on the other hand, efforts to integrate the EDTIB also take risks, as the EU can be seen as protectionist, which can lead other significant arms suppliers, such as the United States of America (USA), to pay back in the same coin (Reis 2021).

\section{EU ground combat forces}

One of the main priorities of the 2018 CDP Revision is the development of Ground Combat Forces Capabilities. The 46 PESCO undergoing projects cover 1) training areas, as well as the 2) terrestrial, 3) maritime, 4) air and 5) cyber environments, and 6) joint enablers (PESCO 2020). Of these projects, $1 / 5$ has more than seven members, of which France, Italy, Spain, and Germany are the most involved ones, while almost half have only three or fewer participants (Nádudvari et al. 2020). Despite the high involvement of the EU Member States in the areas of PESCO capacity, the EU ambition and the revised CRP for 2018 are more comprehensive. Concerning the EU Ground Combat Forces, it is anticipated that they will operate in environments of high threat intensity and face technically advanced adversaries. To that end, the CRP defined as priority areas for land combat a wide range of resources, as identified in Table 1.

Some criticisms are also worth noticing as the vast majority of EU Level of Ambition (LoA) shortfall areas are currently not covered by PESCO projects (Billon-Galland and Efstathiou 2019). According to Billon-Galland and Efstahiou (2019), PESCO has the potential to become relevant if EU Member States show a willingness to go beyond political and industrial obstacles. It is in this respect that the $\mathrm{QH}$ is suitable since PESCO alone should not have a significant impact on the fulfilment of the entire EU CSDP.

We have not identified any PESCO project in one of the CRP areas of Ground Combat Forces (i.e. individual equipment). However, we noted that some EU member states have been conducting research and development (R\&D) activities independently, in collaboration with various national entities. In this context, Portugal can be a relevant player, as it has been carrying out R\&D in this area of activity in the light of the QH Innovation Model. In turn, this indicates that eventually this country may be preparing to lead actions in this field of research, particularly in the context of PESCO, in partnership with other European states.

Table 1. CRP priority in land combat and corresponding PESCO Project (adapted from CDP 2019, 11; PESCO 2020).

\begin{tabular}{ll}
\hline CRP Priority in Land Combat & Current PESCO Project \\
\hline $\begin{array}{l}\text { 1. Current and future armoured land platforms (e.g. Infantry } \\
\text { fighting vehicles and armoured personnel carriers) }\end{array}$ & $\begin{array}{c}\text { Armoured Infantry Fighting Vehicle/Amphibious Assault } \\
\text { Vehicle/Light Armoured Vehicle (AIFV/AAV/LAV) } \\
\text { Indirect Fire Support Capability (EuroArtillery) }\end{array}$ \\
$\begin{array}{l}\text { 2. Next generation of ground-based precision strike } \\
\text { capabilities (e.g. indirect fire support and anti-tank }\end{array}$ & $\begin{array}{l}\text { Integrated Unmanned Ground System (UGS) } \\
\text { weapons) }\end{array}$ \\
$\begin{array}{l}\text { 3. Unmanned ground combat capabilities to } \\
\text { improve force protection in the domains of Counter } \\
\text { Improved Explosive Devices (C-IED), Chemical, Biological, } \\
\text { Radiological, Nuclear, and Explosives (CBRNE) capabilities, } \\
\text { and Personnel Recovery techniques }\end{array}$ & $\begin{array}{l}\text { (DM-DRCP) } \\
\text { 4. Individual soldier equipment }\end{array}$ \\
$\begin{array}{l}\text { No project associated with this CRP Priority has been } \\
\text { identified }\end{array}$ \\
\hline
\end{tabular}




\section{Open innovation and the quintuple helix innovation model}

Since the mid-2000s, innovation ecosystems have been gaining relevance in emerging industries (Arenal et al. 2020). The literature has evolved into several models of N-helix, gravitating around stakeholders, internationalisation, specialisation and ecological conservation (Lew and Park 2020), which offers several opportunities to study these models in the light of various industrial sectors. As previously mentioned, the $\mathrm{QH}$ innovation model is based on the Triple and Quadruple Helix models, adding the "natural environment" to the fifth helix (Figure 1). The QH model combines knowledge, know-how, and the natural environment system in an "interdisciplinary" and "transdisciplinary" structure, as it involves an analytical understanding of the five helices and requires the continuous involvement of the entire disciplinary spectrum as a coherent whole (Choi and Pak 2006; Carayannis and Campbell 2010).

Wars are so intense that they have the potential to alter the biosphere. Therefore, it is acceptable to argue that contemporary military activity can change the function of ecosystems with highly adverse effects. These effects cause dramatic changes in habitat through environmental pollution, population declines, and losses of biodiversity due to acute and chronic effects on both terrestrial and aquatic systems (Lawrence et al. 2015). Examples of these negative changes are associated with contaminants, nuclear radiation, effects of low-precision weapons, etc. However, according to Lawrence et al. (2015), in specific war situations, such as "exclusion zones," it can generate beneficial conditions, protecting the fauna and flora.

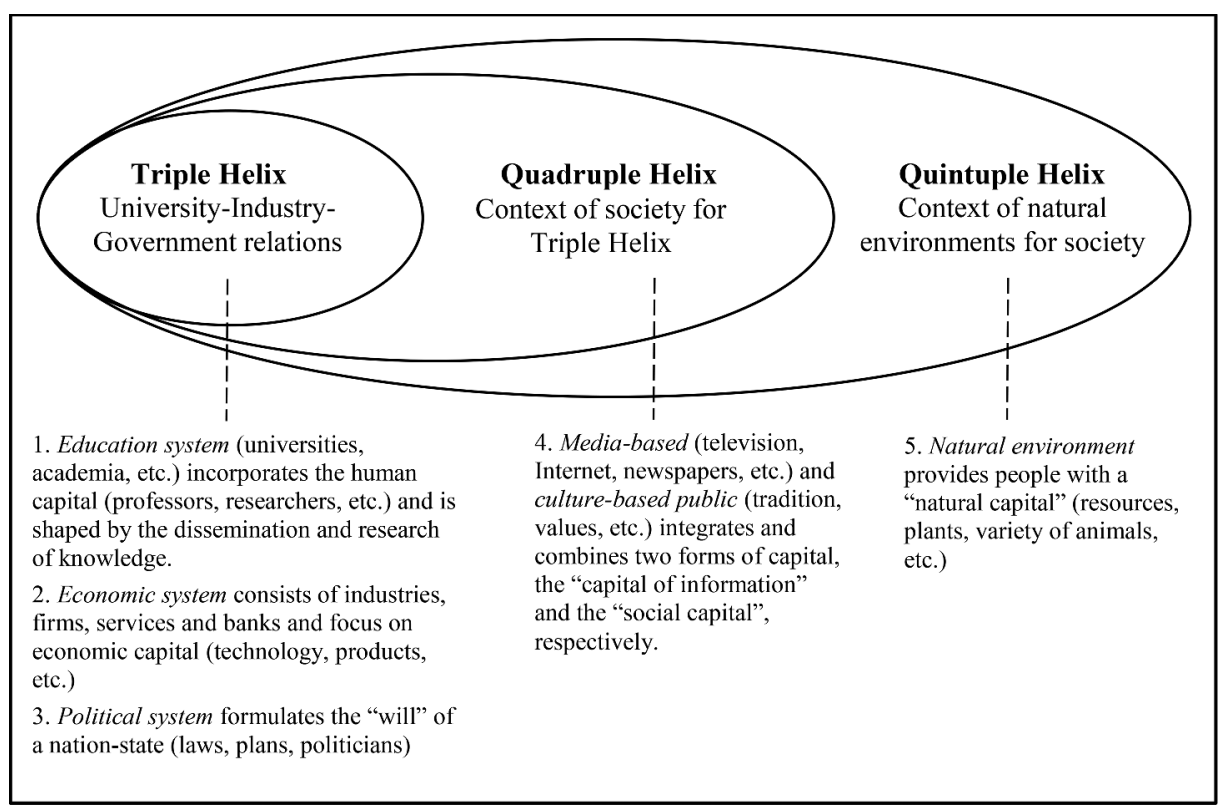

Figure 1. Triple-, Quadruple-, and quintuple-helix innovation models and their subsystems (Adapted from Carayannis and Campbell 2012). 
Regarding the QH's natural environment, it is quite normal for critics to question ecological conservation in the military context. This argument is supported by the perception that environmental harm during a war is generally accepted as an inevitable form of collateral damage (Marler 2013). In contrast, civil society is unwilling to accept environmental damage resulting from military operations (Marler and Moore 2011). Therefore, advancing the ecology of war is a scientific and moral obligation (Machlis and Hanson 2011). Thus, there is a need to counterbalance the intensity of the destructive impacts of war and the reduction of ecosystem and human life degradation.

\section{Methodology}

This research is qualitative, exploratory, and multimethod. Its multimethod nature is explained by the combination of several methods of data gathering and data analysis from two methodological traditions (Seawright 2016, 2). In other words, multimethod studies assume the use of qualitative or quantitative techniques in the same research (Mills et al. 2010), with the intention of understanding and describe a phenomenon for which little is known (Yin 2018). Thus, this article includes two qualitative research strategies, namely a systematic literature review (Torgerson 2003; Petticrew and Roberts 2008) and a single case study research (Yin 2018). Both strategies have the intention of complementing each other (Reis et al. 2020), as the SLR provides the conceptual basis from a "replicable, scientific and transparent" process (Tranfield et al. 2003, 209), and the case study aims to support, explore and explain a reality (Gerring 2006).

\section{Systematic literature review}

The SLR was performed according to Preferred Reporting Items for Systematic Reviews and Meta-Analyses (PRISMA) by Moher et al. (2009). As shown in Table 2, in the identification phase, we analysed the entire scope of the research using appropriate keywords. Then, the screening phase filtered documents according to quality (journals) and comprehension (language) criteria. Next, the eligibility is related to accessibility and inclusion of relevant documents not previously identified in the Scopus database.

The search was carried out on March $9^{\text {th }}, 2021$. The use of Scopus is justified by its broad coverage of peer-reviewed literature, multidisciplinarity, ability to apply filters, and the easy retrieval of bibliometric data. The coverage selection took into account the analysis and pre-test of a series of databases, such as the Web of Science, B-On, and

Table 2. Four phases of PRISMA protocol.

\begin{tabular}{|c|c|c|}
\hline & $\mathrm{n}$ \\
\hline \multicolumn{3}{|c|}{ Identification } \\
\hline & "Defence Industry" AND "Innovation" (All) & 25,909 \\
\hline \multicolumn{3}{|c|}{ Screening } \\
\hline & Title, abstract, and keywords (Title-Abs-Key) & 198 \\
\hline & Journal (Articles) & 99 \\
\hline & Language (English) & 80 \\
\hline \multicolumn{3}{|c|}{ Eligibility } \\
\hline & Repeated articles removed & 79 \\
\hline \multicolumn{3}{|c|}{ Included } \\
\hline & Included studies (+1 article) & 80 \\
\hline
\end{tabular}


EBSCO. Academic search engines, such as Google Scholar, were initially excluded because they include non-peer-reviewed literature and have a limited scope for applying filters. In addition, Scopus also emphasises the human and social sciences compared to similar databases (Martín-Martín et al. 2021), and has been used in similar research (Reis 2021).

We started the SLR with the identification criteria, using the terms "defence industry" AND "innovation" in all search fields. The search fields were then filtered by "title, abstract and keywords." The screening criteria also included articles from Journals, as they are generally of better quality, although we know that some relevant articles may have been excluded. To increase comprehension, we selected documents in English; otherwise, we could have interpretation bias. We decided not to include any time restrictions so as to have a broader understanding of the literature. The process continued until the duplicate articles were excluded (due to a database error). Finally, we have included an article about the defence industry within the scope of the triple helix in Portugal. After applying the PRISMA protocol, the final result was 80 peer-reviewed articles.

\section{Case design}

This research has the Portuguese defence industry (idD - Portugal Defence) as a unit of analysis. Its centrality is justified by the geographical position of Portugal as the most western country of Europe, enhancing the trans-Atlantic relations of the EU and their American allies. As a founding member of the North Atlantic Treaty Organization (NATO), member of the EU, and member of the Eurozone, Portugal is a relevant entry point to the centre of Europe. Moreover, Portugal is also a key player in the Community of Portuguese Speaking Countries (CPLP), bridging South America (Brazil), Africa (Angola, Mozambique, Cape Verde, São Tomé and Príncipe, Guinea-Bissau and Guinea Equatorial), and Southeast Asia (Democratic Republic of Timor-Leste).

The idD carries out the sectorial defence policy by consolidating a public business decision centre (idD 2021). IdD intends to leverage financial instruments, both national and European, to create value within the framework of the European defence policy. Thus, it promotes, develops, and supports the organisations that integrate the Portuguese Defence Technological and Industrial Base (DTIB) in coordination with the DirectorateGeneral for National Defence Resources (DGNDR). The latter State agency (DGNDR) develops and coordinates the national defence policies for human resources, materials, and infrastructures (DGNDR 2021b). In turn, the DTIB is composed of public or private organisations operating in the defence and security sectors. These organisations are mainly composed of SMEs (Small and Medium-size Enterprises) organised by clusters (Table 3).

Overall, DTIB brings together more than 380 public and private SMEs active in Research and Technological Development (RTD). Despite their arrangement in clusters, it is typical for organisations belonging to different clusters to cooperate with each other, seeking synergies, which is seen as an advantage.

To achieve the proposed objectives and adequately answer the research questions, this case study collects data from several sources, namely in-depth semi-structured interviews, participant observation (i.e. webinars, ${ }^{1}$ seminars, ${ }^{2}$ workshops ${ }^{1}$, and focus 
Table 3. Portuguese defence technological and industrial base (adapted from BTID 2019).

\begin{tabular}{|c|c|}
\hline Cluster & Number of Companies \\
\hline 1. Aeronautic & 30 \\
\hline 2. Communications and Information Systems & 57 \\
\hline 3. Construction and Engineering & 31 \\
\hline 4. Cybersecurity & 8 \\
\hline 5. Energies & 12 \\
\hline 6. Environment & 13 \\
\hline 7. Footwear & 6 \\
\hline 8. Goods and Catering & 6 \\
\hline 9. Health & $7 \square$ \\
\hline 10. Land & 5 \\
\hline 11. Naval & $19 \square$ \\
\hline 12. Organizations & 18 \\
\hline 13. Research & $26 \square$ \\
\hline 14. Robotics and Automation & 8 \\
\hline 15. Security & 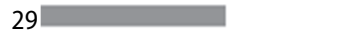 \\
\hline 16. Services & 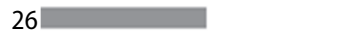 \\
\hline 17. Technological Materials & $37 \square$ \\
\hline 18.Textile & $24 \square$ \\
\hline 19. Transports & 12 \\
\hline $\begin{array}{l}\text { 20. Unmanned Aerial Vehicles (UAV)-Unmanned Underwater Vehicles } \\
\text { (UUV)-Unmanned Ground Vehicles (UVG) }\end{array}$ & 8 \\
\hline
\end{tabular}

groups ${ }^{3}$ ), and official documents. The semi-structured interviews incorporated open questions to enable participants to narrate their experiences (Galletta 2013). However, the focus of the questions was deliberately and carefully linked to the research theme through a protocol designed for this purpose (Castillo-Montoya 2016). The interviews were conducted by video call via Colibri/Zoom, allowing the research to develop the conversation. After the meeting, the recording was transcribed verbatim and sent to the participants for validation. In cases where the answers were not so clear, we returned to respondents to collect more data, resorting for that purpose to a digital whiteboard tool (Miro's online Mind Map). Miro whiteboard enabled brainstorming and allowed to map processes online until a deeper comprehension of the phenomenon was achieved. The respondents were selected using convenience and snowball sampling (Merriam and Tisfell 2015). Although guidelines for determining non-probabilistic sample sizes are practically non-existent (Guest et al. 2006), we stopped collecting data when we 
reached theoretical saturation. That is, the interviews were carried out to "the point where no more could be added" (Costley and Fulton 2018, 178). Overall, we conducted 17 in-depth interviews. This number is within the range typically suggested in the literature, which generally points to 15-25 interviews to obtain a rich understanding of the phenomenon under study (Hennink et al. 2017; Marshall et al. 2013; Saunders and Townsend 2016).

Regarding participant observation, the researchers assumed an active role within the event (Mills et al. 2010). Therefore, the researchers were directly involved in webinars and seminars; through networking, focus groups were also carried out. Although participant observation did not offer direct data on the broader context of those being observed (Berg 2004; Lune and Berg 2017), it allowed establishing purposeful interactions to collect data for corroboration and triangulation purposes. After the workshops were held, we brought together a relatively small group of participants to enable brainstorming and allow everyone to get involved in the discussion. The focus groups proved to be very relevant, as they made it possible to gather groups of experts who participated in the workshops and who were highly involved in the idD - Portugal Defence.

This article also includes a third source of data collection, consisting of organisational documents (Given 2008) retrieved from the official websites of the idD - Portugal Defence, the Portuguese Defence Technological and Industrial Base (DTIB), and the Directorate-General for National Defence Resources (DGNDR). Regarding the ethical guidelines, a document was presented to the participants with relevant and detailed information about the research. Moreover, a signed and informed consent form (including consent for audio recording) was obtained and documented in the light of the Declaration of Helsinki (2013).

The data were analysed using thematic analysis techniques (Sundler et al. 2019) and content analysis (Vaismoradi et al. 2013; Krippendorff 2018), with the aid of computerassisted data analysis software (CAQDAS) called NVIVO - QSR International (Version 11) (Neuendorf and Kumar 2015; Woolf and Silver 2017). We started by classifying the most relevant phrases and ideas, followed by the coding process and text interpretation (Gibbs 2018). As coding requires substantial effort, creativity and self-reflection (Drisko and Maschi 2016), we opted for two coding approaches - deductive and inductive. In the thematic analysis, a deductive approach was used to generate a list of codes from the literature, whereas we used an inductive approach in the content analysis. The inductive approach is typically suited to situations where the researchers have minimal knowledge about the research problem, which was the case with the relationship between open innovation, the defence industry, and the increase in military capabilities. Once the

Table 4. Summary of the methodological approach.

\begin{tabular}{lll}
\hline Methodological process & \multicolumn{2}{c}{ Approach used } \\
\hline $\begin{array}{l}\text { Research nature: } \\
\text { Research type: }\end{array}$ & Qualitative Research & \\
Research strategy: & Multimethod Research & \\
Sources of data collection: & Systematic Literature Review & Case Study Research \\
& Scopus database & $\begin{array}{c}\text { Semi-structured interviews } \\
\text { Participant observation } \\
\text { Official documents }\end{array}$ \\
& & Content analysis \\
Data analysis techniques: & Thematic analysis & Inductive \\
Coding approach: & Deductive & \\
\hline
\end{tabular}


patterns were found in the codes, it was possible to identify the most relevant categories and topics (Tracy 2019), generating an overview of the data. Overall, the data analysis techniques were helpful to code and analyse a large volume of data (i.e. this study yielded 784 pages). Table 4 presents a summary of what we have been discussing.

Reliability demonstrates that the operations of a study can be repeated with the same results (Yin 2018). In that regard, we administered the same protocol to all respondents so that the interview process was consistent. The interview transcriptions were also sent to respondents to see if the researchers understood what the interviewee really meant. To ensure validity, this research used triangulation and member checks. That is, we use multiple sources of data collection to confirm the emerging findings and co-authors expertise to verify the entire data analysis process for inconsistencies. The connection between reliability and validity rests on the assumption that a study is more valid if repeated observations or replication of the entire study produce the same results (Merriam and Tisfell 2015). Merriam and Tisfell (2015) also argue that the logic depends on the repetition of events to establish the truth, though several people who experience the same phenomenon do not make the observations more reliable because they can observe it differently.

\section{Results and discussion}

This section is organised into two sub-sections. First, we describe the state-of-the-art of the defence industry and open innovation, along with the existing conceptual frameworks in the light of the Portuguese defence industry. This section also includes the results of the analysis of the case study, showing the contributions of the various sources of data collection so as to provide a holistic and integrated view of the phenomenon.

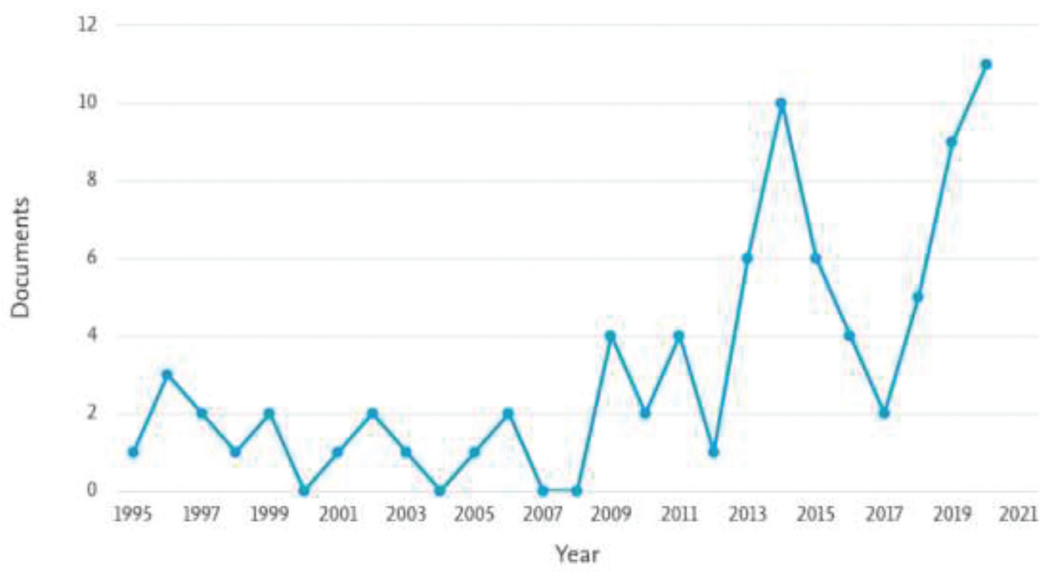

Figure 2. Documents by year (retrieved from Scopus database). 


\section{Findings from the SLR}

From a timeline perspective, scientific research in defence innovation is far from being straightforward. The most relevant moments are the peak in 2014 and the growing number of scientific research since 2018 (Figure 2). The peak in 2014 may be due to several factors, such as: 1) the liberalisation of defence firms and the erosion of America's defence innovation; 2) the contribution of defence innovation to the People's Republic of China's (PRC) economic growth; and 3) the environmental footprint reduction of the European Defence sector.

Writing about the US defence innovation, Steinbock (2014) argues that, despite its resilience and superiority, the defence industry shows structural erosion and relative decline. The decline in the US industrial base is related to short-term policies, erosion of domestic defence innovation, and high production costs for limited budgets. In the absence of significant change, the US will tend to lose power to other actors, such as the EU and PRC. On the other hand, Blom et al. (2014) suggest that EU defence companies are becoming more efficient and less dependent on public procurement and, therefore, are more likely to share knowledge and collaborate. Thus, it is likely that the dynamics among companies will lead to an increase in the export propensity of the industry and to a less concentrated export market. The argument by Blom et al. (2014) is visible in this case study, as it is possible to notice that EDTIB increasingly establishes a dynamic between companies, although with some support from the State. In comparison, the Chinese defence industry is very limited in knowledge production, since the demand for technology comes mainly from civilian areas (Yuan et al. 2016). That is, the defence industry must be integrated into the civilian sector (dual-use) in order to contribute to economic growth more efficiently. In that regard, Reis (2021) also argues that it seems evident that the greater the integration between the defence industry and civil society, the greater the propensity for stability.

The third most relevant milestone in 2014 is related to the climate and renewable energy objectives of the EU in its efforts for sustainability, environmental protection, and energy efficiency in the various European defence sectors (Fiott 2014). Fiott (2014) argues that the defence sector is one of the biggest consumers of energy (European Defence Agency 2012), so it is natural that it becomes more environmentally friendly. The reality is that the European defence industry is far from being a "green player," although there is a strong desire to become more environmentally friendly. In this regard, costeffectiveness and public opinion seem to be the most relevant incentives for military engagement with green practices. Finally, Fiott $(2014,274)$ also mention that ecological efforts in the European defence sector can be divided by actors: - by the military, such as environmental audits during and after military operations; - by defence companies, in technological innovation to increase military capabilities, as well as in logistics and production processes; - by governments, through European and national regulatory and legislative measures. In this article, we will focus on the second action, that is, on military innovation, logistics, and increase of military capabilities of ground forces.

The topics responsible for the growing number of publications since 2018 are mainly related to defence innovation and technology transfer of the Spanish defence industry (Briones-Peñalver et al. 2020; Oliva et al. 2019; Callado-Muñoz et al. 2020), the expansion of the Chinese Defence industry (Béraud-Sudreau and Nouwens 2021; Dominese 2020), 


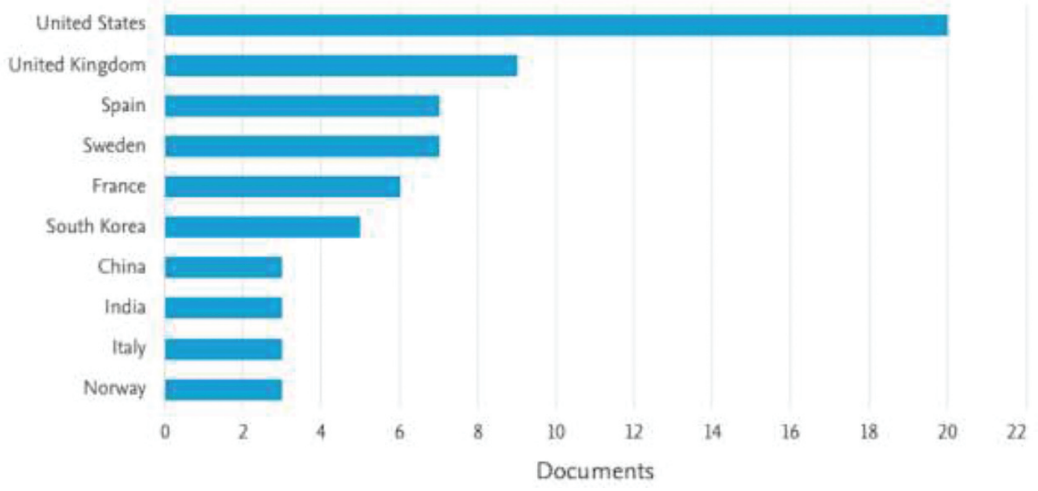

Figure 3. Documents by country and territory (up to 15 countries/territories) (retrieved from Scopus database).

and the Brazilian R\&D projects (Bernat and Karabag 2018; Silva and Olavo-Quandt 2019; Fernandes et al. 2020). The most notable investment in research refers to the Spanish defence industry, which is also shown in Figure 3 (top 3 countries). The manuscripts from Spain show that strategic alliances favour knowledge and innovation management. In other words, the cooperation agreements favour the process of absorption and diffusion of innovation, facilitating not only learning, but also the transmission of knowledge. This analysis aligns with the case study described in the next sub-section, where the strategic alliance between EDTIB companies allowed better dissemination of knowledge and commercialisation of innovative military products.

The highest number of articles refer to defence industry innovation in the USA, United Kingdom (UK), and the EU (Figure 3). Reis (2021) observed that the referred countries have been announcing public measures to support their defence industries. PRC is in $7^{\text {th }}$ place as it still needs to reach a stage of radical or disruptive innovation, for which it still lacks resources and R\&D personnel, together with investment in financial resources and willingness to take risks (Béraud-Sudreau and Nouwens 2021). The

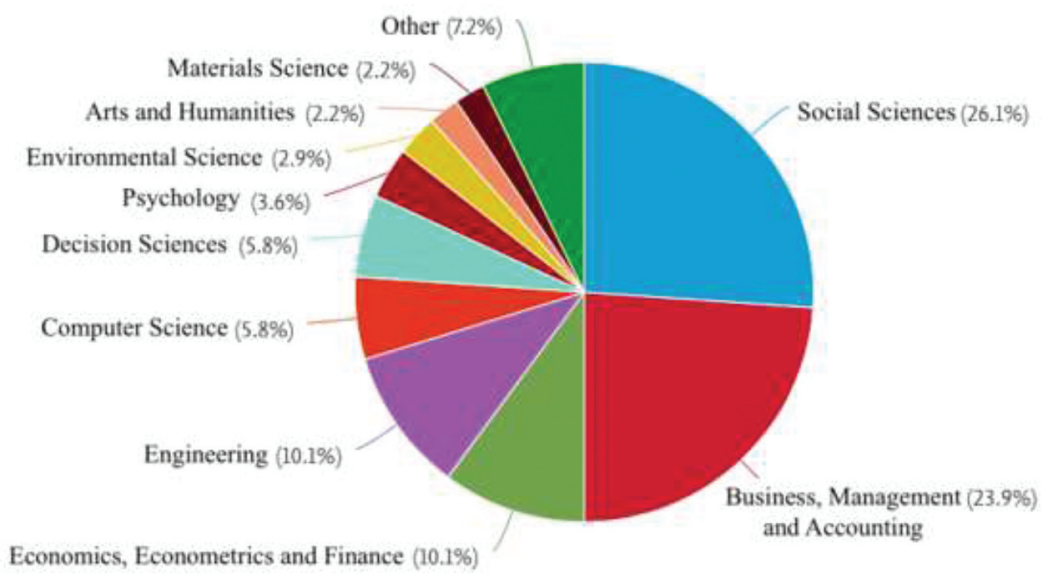

Figure 4. Documents by subject area. 
previous argument is also justified by Béraud-Sudreau and Nouwens (2021), who stated that although there are international classifications of Chinese's global defence companies, PRC maintains secrecy of information, resulting in the exclusion of State defence companies from databases.

Regarding the research areas (Figure 4), we were expecting to find the Business, Management, and Accounting, as well as Engineering, as the strongest areas in terms of defence innovation. However, the social sciences is the area that stands out, and there are some explanations for why this happens. If we take a closer look, we realise that social sciences have a relevant role in maximising the social returns of technological and industrial innovation developed by the defence. In that regard, Yuan et al. (2016) claim that defence innovation has a spill-over effect on the sectors of civil society, and gives some examples of sectors that have benefited from the transfer of defence technological innovation to civil society, as is the case of: 1) the development of the atomic bomb (i.e. Manhattan Project) that created the current nuclear industry; 2) the development of computer hardware and software (applications) that was extended to civil society, resulting in a profound social change; or 3) the United States Defence Advanced Research Projects Agency (DARPA), which developed the ARPNET network, the predecessor to the Internet. Considering that a large part of the developments comes from the USA, with the end of the cold war, we started to observe a globalised integration of civil-military innovation, which has benefited governments, military institutions, defence companies, and civil society.

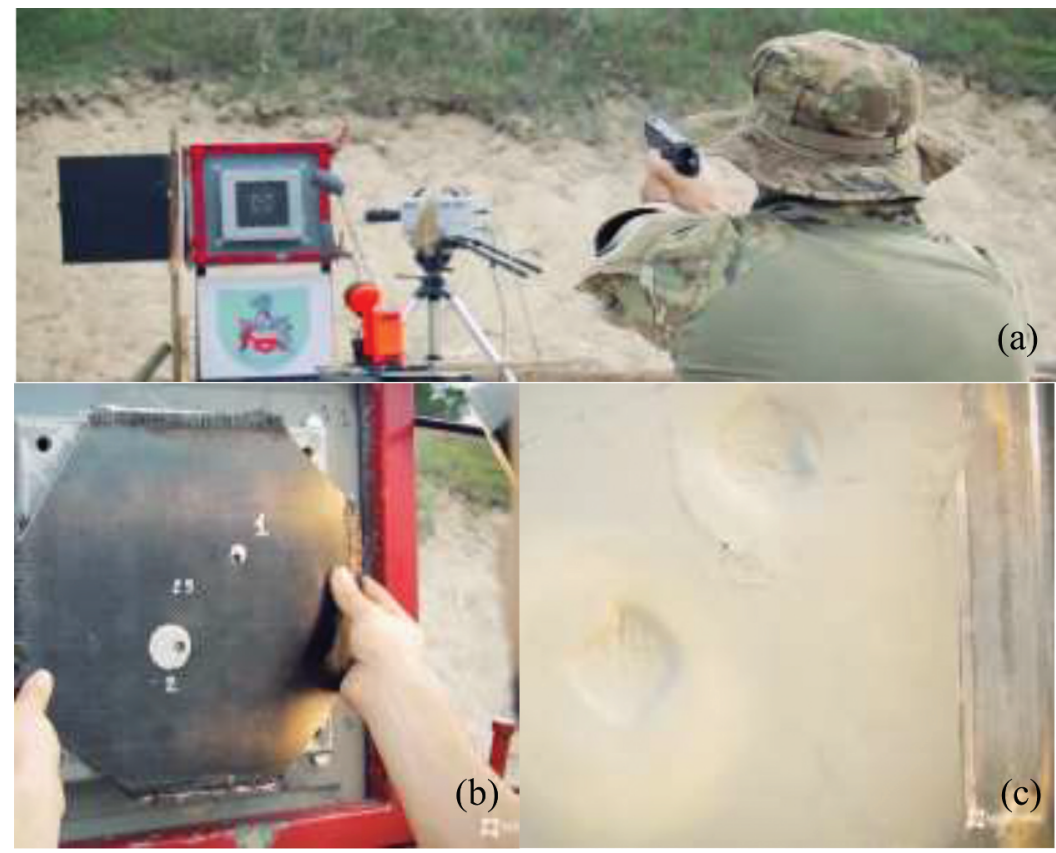

Figure 5. Pre-test of the bulletproof vest (Adapted from Alexis Vilaça 2021): (a) military conducting the pre-test; (b) target impacts; (c) effects on target. 


\section{Findings from the case research}

Open innovation is not simply an outsourcing of research, development, and innovation (R\&D\&I) activity, but an integration of internal and external competencies (Buganza and Verganti 2009). While the innovative and high-tech industries demand a high investment in R\&D\&I, idD soon realised that it could not act in isolation. Therefore, idD sought to work closely with universities and the armed forces. This synergy benefited all stakeholders, particularly the armed forces, which saw their military capabilities increased due to the development of better individual equipment. According to Chesbrough (2003), a firm's relationship with external stokeholds may take place in three different stages: the fuzzy front-end, while accessing to new knowledge; the development, buying or selling solutions; and, commercialisation, buying and selling end products or components. In this case study, this has been achieved through outside-in collaboration with universities and inside-out by collaborative relations with the armed forces, which carried out pretests and field tests (Army tested) to improve the defence products (Figure 5).

As presented in Table 3, the Portuguese Defence Industry has a high segmentation, with a total of 380 public and private companies, operating in 20 distinct segments. For that reason, the Portuguese Ministry of National Defence (MND) decided to promote a consortium entitled "AuxDefence." That partnership brought together the Portuguese Armed Forces (Army and Air Force), national (University of Minho) and international universities (Hong Kong Polytechnic University and British Plymouth University), and several Portuguese Defence Companies (Latino Group - textile; LMA - textile; Fibrauto - technological materials; IDT Consulting - services; Sciencentris - technological materials). The materials developed resulted from the scientific research and technological development in areas such as, for example, advanced materials, which were designed to build more resistant and lighter equipment, i.e. (a) helmet, (b) bulletproof vest, (c) knee and elbow pads (Figure 6).

As the AuxDefence project uses knowledge generated by universities, the consortium enabled the development of advanced composite materials, i.e. auxetic textile structures. The auxetic phenomenon is associated with materials with a negative Poisson's ratio that will expand transversally upon the application of tensile forces and vice versa (Lolaki et al. 2020, 1). The auxetic fibrous structures allowed the reinforcement of polymeric matrices and the manufacture of fibre in military equipment garments and components. Despite the abundance of studies on the theory of auxetic materials, few studies have been successful in the transition to practice and production on the desired commercial scale, at least with regard to military equipment (Underhill 2014). Thus, the ultimate objective of AuxDefence is twofold: to develop innovative defence products and protect ground military forces in the most diverse theatre of operations. In sum, the AuxDefence intends to create innovative products to be used by ground military forces, which are based on advanced auxetic structures with high performance in terms of mechanical protection, i.e. technologies capable of absorbing impact and with high capabilities to resist cutting and perforation. Concerning the RQ1, open innovation is improving the defence industry to the extent that it has allowed to combine the contribution of universities (fuzzy front-end), companies (development and commercialisation), and the Armed Forces (Army tested and acquisition). As for the ground forces, they are also primary beneficiaries since their survivable capabilities on the battlefield increase. 


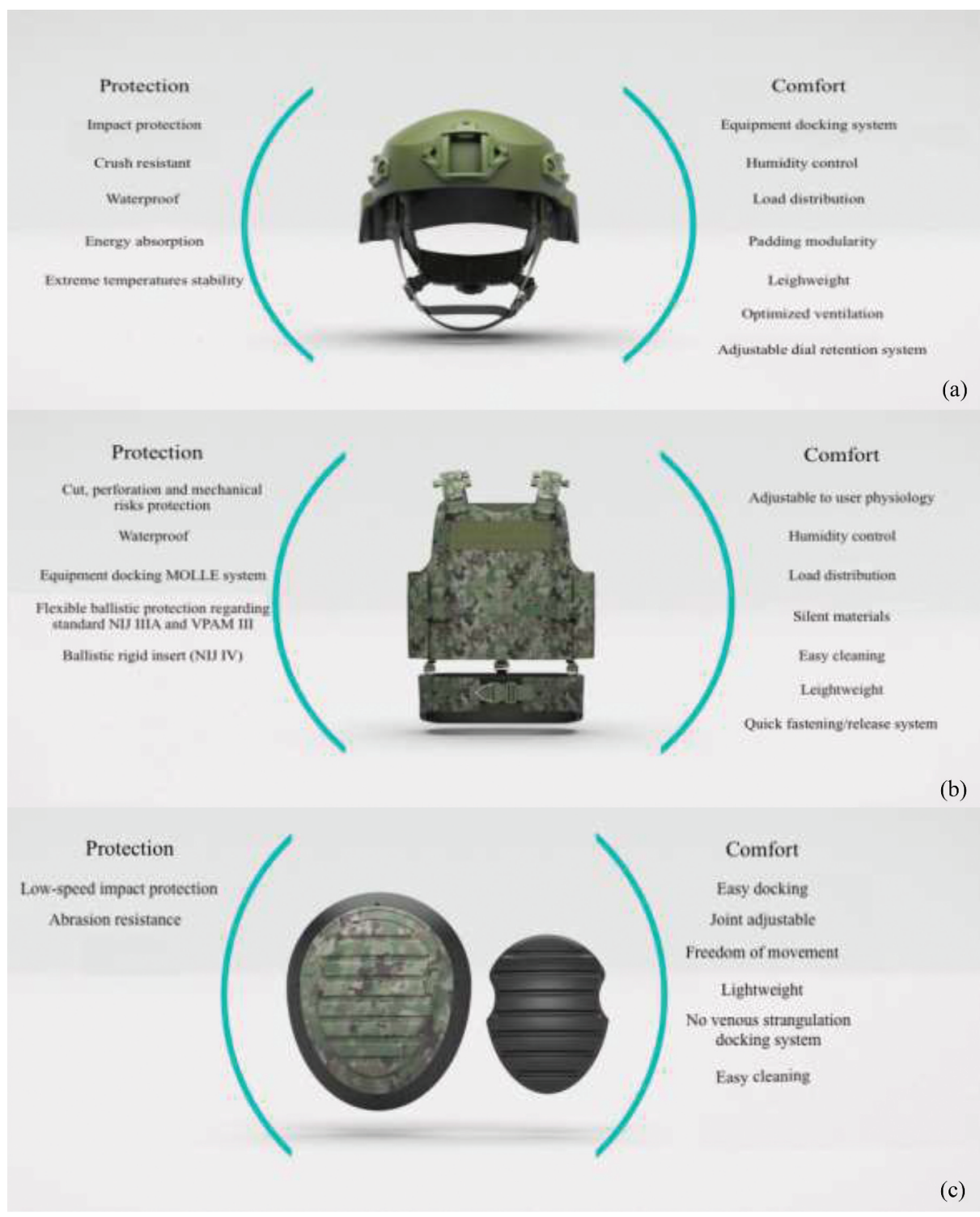

Figure 6. Self-defence equipment for ground combat forces (Adapted from Alexis Vilaça 2021): (a) helmet; (b) bulletproof vest; (c) knee and elbow pads.

In the context of the quintuple helix, it is foreseen the commercialisation of new military products to external military markets. While the project falls under level 7 of the Technology Readiness Level scale, it has in view the eventual industrial and commercial application (Figure 7). It is expected that the transfer of knowledge to companies involved in the project/consortium allows to industrialise and guarantee its commercialisation in the civilian market. The interest is associated with sectors of activity where the needs for energy absorption, resistance to impact, hardness, and toughness are essential (Evans and Alderson 2000; Wang and $\mathrm{Hu}$ 2014). For instance, auxetic composite 


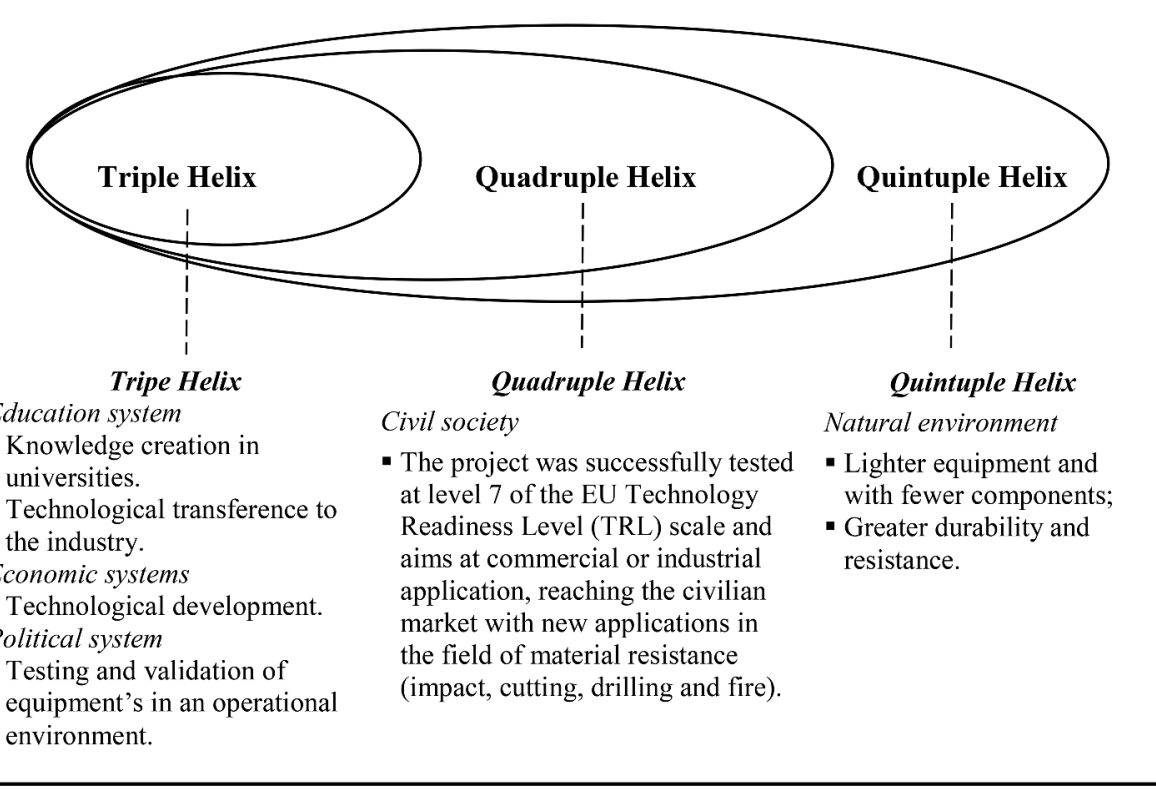

Figure 7. Self-defence equipment of Portuguese ground combat forces.

materials present great potential applications where energy absorption is a crucial factor in protection, such as sports activities (Steffens et al. 2021), aerospace (Wang et al. 2016), among others.

In addition to cooperation between military entities and the business community, the production of knowledge in universities opens doors to other innovation and technological development (I\&DT) projects, scientific production (Fangueiro and Rana 2019, 2020), and the development of patents (Ayerbe et al. 2014). The argument above aligns with Simões et al. (2020) article, who analysed 145 projects of the Portuguese Ministry of Defence and found that academia represented more than $90 \%$ of the projects, $40 \%$ of those have a dual-use application. The defence industry also has some specificities when compared to the civil industrial sector, mainly regarding strategic alliances. As argued by Langlois et al. (2020), previous research opposed secrecy to open innovation. However, the development of advanced military technologies can likely be carried out on the basis of trust and mutual respect between organisations, as noted in this case. In situations where the bond of trust is broken, legal mechanisms allow organisations to be excluded from these and future projects.

Regarding the RQ2, the developed products (i.e. helmet, bulletproof vest, knee and elbow pads) also had an environmental concern (Figure 7); they reduced the use of materials and their weight by about $20 \%$ (without losing the expected performance) when compared to the previous equipment in use by the Portuguese armed forces. Through the use of fibrous materials, such as high-performance polyethylene fibre, it was also possible to improve the Portuguese military materials' comfort and ergonomic component. In this regard, anthropometric studies were carried out to adapt the uniform to the soldiers' ergonomics. The reduced weight and better ergonomics of the new uniform allow for 
increased speed and mobility on the battlefield. For instance, AuxDefence's new developments enabled the modular helmet to resist impacts of $9 \mathrm{~mm}$ firearm projectiles, while the ballistic vest can withstand $7.62 \mathrm{~mm}$ automatic rifle projectiles. This resistance is partially due to carbon nanotubes, which, in practice, are carbon sheets wrapped in a cylinder that increase the mechanical capabilities of the product when compared to traditional materials (i.e. steel).

The innovative materials were also tested in an operational environment. In that regard, the Portuguese military personnel, deployed in Besmayah - Iraq, whose mission was to train the Federal Police of the Iraqi Security Forces, tested all the developed equipment. We had the opportunity to verify that the military uniforms and tactical equipment were subjected to severe thermal $\left(<45^{\circ} \mathrm{C}\right)$ and abrasion conditions. Thus, the integration of textile technologies in the military arena has been instrumental due to its vast, diverse, and complex performance. Some examples aim at: 1) visual protection (camouflage); 2) mechanical protection (ballistic, thermal, etc.); 3) chemical, biological and radiological protection (anti-bacteria, anti-viruses, etc.); and 4) ecological protection, paying due regard to ecosystems and the environment. These are just a few examples that illustrate the relevance of certain military technologies and how they can protect military forces in the light of the quintuple helix innovation model. Although this article presents only one exploratory case, it shows the academic community the relevance of open innovation in building military technologies to protect EU forces in their peace support missions, as well as the need to transfer these technologies to the civilian community.

\section{Conclusions}

The conclusions are divided into four parts. The first and second parts focus on contributions to theory and practice. Then, we present the limitations of both research strategies (i.e. the systematic review and the case study). Finally, we offer some suggestions for future research so that other researchers can follow this study.

\section{Contributions to theory}

This article builds upon the existing theory (Simões et al. 2020), seeking to explore the defence industry in what is known as the quintuple helix innovation model. Thus, this article goes beyond the recent findings of Reis (2021) that suggest a possible existence of quadruple helix within the scope of the defence industry.

The key arguments that support our results can be summarised in three parts. First, it may be helpful in highly segmented industries to create an entity to manage the defence projects (such as AuxDefence). Second, relevant theoretical studies have not been successful in the transition to practice and the desired commercial scale. In that regard, the defence projects have enabled the development of practical applications of particular academic works, as is the case of polymeric auxetic materials, who are posing new and exciting opportunities in the field of defence applications. Thus, it was possible to give life to new textile products based on advanced technologies for the benefit of the end-user. After being tested and produced on a large scale for the armed forces, the identified selfdefence equipment is in condition to be adapted and commercialised to the civilian market (e.g. aerospace, aeronautics, etc.). Finally, it was possible to ascertain that there is 
a growing concern for the natural environment. Although ecological sustainability was not the primary aim, when combined with military needs and expectations, the project has enabled the development of products with greater durability (e.g. abrasion resistance) and consequently less waste.

\section{Managerial contributions}

Regarding the managerial contributions, it was possible to verify that the triple helix innovation model is not an end point, but an intermediate framework that can be extended to the society and the natural environment dimensions. It is recommended that DTIB managers continue their efforts to transition from technological developments in defence to possible commercialisation in civil society. Concerns about protecting the natural environment are increasingly common (Camilleri 2020; Dzwigol et al. 2020), and the defence industry is not immune to such matters. Therefore, managers working in the defence industry must consider analysing the natural environment in their proposals, despite the incidence of scientific studies being extremely low compared to other sectors of activity. Finally, there are some relevant opportunities about the R\&D\&I under PESCO that could be used to develop innovative products for ground military forces. These opportunities can be seized by managers who wish to boost their companies in the military field through EU financial resources.

\section{Research limitations}

This article is not free of limitations. While the systematic review provides a snapshot of a given reality, this research does not cover the entire body of knowledge. However, this limitation is mitigated by the case study, which provides new and complementary outcomes. Moreover, Scopus is constantly being updated with recent and relevant articles, and some of them will likely be left out. Thus, it is necessary to continue investigating the topic to keep the scientific community updated with the most current knowledge. Recognising the limitations above, we believe that the systematic review still brings added value, as it contributes to a more robust conceptual framework that would not otherwise be possible.

Regarding the case research, one of the limitations stems from the lack of confidence in the credibility of research procedures. This limitation is partly explained by the assumption that quantitative data is more robust when compared to qualitative data since the latter consists of non-numerical information. We believe that the systematic and careful use of the case study can overcome the presented limitation. For instance, to mitigate the limitation above, we used triangulation of several sources of data collection to confirm the findings and interpretations.

Another snag refers to the inability to generalise the results of a case study to a broader level. In fact, we will refer this challenge to future studies, as we do not know whether the quintuple helix innovation model applies to other military contexts and realities. 


\section{Recommendations for future research}

The Portuguese defence industry is starting to have concerns about the natural environment, as it has developed and produced military equipment with fewer components, lighter and highly durable. However, as (Machlis and Hanson 2011) advocated, more research is needed for warfare ecology, notably with regard to the use of ecological models to integrate various impacts of war at the ecosystem level (Machlis and Hanson 2011). In other words, there is still a lack of articles published about the quintuple helix innovation model in relation to the defence industry. Future research can also address the issue of generalisation by extending this research to countries outside the European context, as they may operate differently from Portugal.

\section{Notes}

1. Webinars and workshops were organized by the: a) idD - Portugal Defence; b) AuxDefense - Advanced Materials for Defence Seminars; c) Portuguese Military Academy.

2. Seminars were organized by the: a) Portuguese Presidency of the Council of the European Union; b) AuxDefense - Advanced Materials for Defence Seminars; c) Portuguese Military Academy.

3. Focus groups were organized following the seminars and workshops with the experts in the field.

\section{Disclosure statement}

No potential conflict of interest was reported by the author(s).

\section{Notes on contributors}

João Reis, born in 1982, Major, Ph.D. in Industrial Engineering; Professor of Operations Management, Logistics and Supply Chain Management; Researcher in the fields of Defence Industry, Cyber-physical Systems, Intelligent Decision Support Systems and Industry 4.0; Researcher at EIGeS and GOVCOPP.

Nuno Melão is an assistant professor at the Department of Management, School of Technology and Management of Viseu, Polytechnic Institute of Viseu, Portugal. He received his Ph.D. in Management Science from Lancaster University Management School, UK in 2001. His conducts his research at the $\mathrm{CISeD}$ of the Polytechnic Institute of Viseu. His research interests include quality management and process management.

Joana Costa held a Post-Doc in Economics from FEP University of Porto in the field of "Innovation Persistence and National Innovation Context - The Role of Open Innovation." $\mathrm{PhD}$ in Public Policy - Economics of Innovation from the DCSPT, University of Aveiro and a Master in Economics at FEP, University of Porto, as well as a Degree in Economics from EEG, University of Minho.

Bohuslav Pernica, born in 1973, lieutenant colonel (ret.), Ph.D. in military economics in 2003 2010-2014 a military adviser to Deputy minister; a co-editor of the Czech White Paper on Defence in 2011; he focuses on issues of All-Volunteer Force, military spending, defence industry, Security Sector Reform in the post-communist countries, and corruption in his research. 


\section{ORCID}

João Reis (D) http://orcid.org/0000-0002-8504-0065

Nuno Melão (D) http://orcid.org/0000-0002-1359-3437

Joana Costa (D) http://orcid.org/0000-0001-7514-9836

Bohuslav Pernica (ID http://orcid.org/0000-0002-1087-6888

\section{References}

Costley, C., and J. Fulton, Eds. 2018. Methodologies for Practice Research: Approaches for Professional Doctorates. Thousand Oaks, California, USA: SAGE Publications.

Fangueiro, R., and S. Rana, Eds. 2020. Advanced Materials for Defense: Development, Analysis and Applications. Vol. 4. Cham, Switzerland: Springer Nature.

Arenal, A., C. Armuña, C. Feijoo, S. Ramos, Z. Xu, and A. Moreno. 2020. "Innovation Ecosystems Theory Revisited: The Case of Artificial Intelligence in China." Telecommunications Policy 44 (6): 101960. doi:10.1016/j.telpol.2020.101960.

Ayerbe, C., N. Lazaric, M. Callois, and L. Mitkova. 2014. "The New Challenges of Organising Intellectual Property in Complex Industries: A Discussion Based on the Case of Thales." Technovation 34 (4): 232-241. doi:10.1016/j.technovation.2014.01.001.

Béraud-Sudreau, L., and M. Nouwens. 2021. "Weighing Giants: Taking Stock of the Expansion of China's Defence Industry.” Defence and Peace Economics 32 (2): 151-177. doi:10.1080/ 10242694.2019.1632536.

Berg, B. 2004. Qualitative Research Methods for the Social Sciences. 4th ed. MA, USA: Pearson Education Company.

Bernat, S., and S. Karabag. 2018. “Accumulating Technological Capabilities through R\&D Projects: Studies on the Brazilian Defence Industry." International Journal of Technological Learning, Innovation and Development 10 (3/4): 203-230. doi:10.1504/IJTLID.2018.093721.

Billon-Galland, A., and Y. Efstathiou. 2019. “Are PESCO Projects Fit for Purpose?” European Leadership Network, February 20: 1-12.

Blom, M., F. Castellacci, and A. Fevolden. 2014. "Defence Firms Facing Liberalisation: Innovation and Export in an Agent-based Model of the Defence Industry." Computational and Mathematical Organization Theory 20 (4): 430-461. doi:10.1007/s10588-014-9173-6.

Briones-Peñalver, A., J. Bernal-Conesa, and C. de Nieves Nieto. 2020. "Knowledge and Innovation Management Model. Its Influence on Technology Transfer and Performance in Spanish Defence Industry." International Entrepreneurship and Management Journal J 16: 1595-1615. doi:10.1007/s11365-019-00577-6.

Brunswicker, S., and W. Vanhaverbeke. 2015. "Open Innovation in Small and Medium-sized Enterprises (Smes): External Knowledge Sourcing Strategies and Internal Organisational Facilitators." Journal of Small Business Management 53 (4): 1241-1263. doi:10.1111/jsbm.12120.

BTID. 2019. "Catálogo BTID (Base Tecnológica e Industrial de Defesa)". Portuguese Defence Technological and Industrial Base. Accessed 14 March 2021. Accessed March 14 . https:// www.iddportugal.pt/wp-content/uploads/2020/02/Catálogo-BTID-2019

Buganza, T., and R. Verganti. 2009. "Open Innovation Process to Inbound Knowledge.” European Journal of Innovation Management 12 (3): 306-325. doi:10.1108/14601060910974200.

Callado-Muñoz, F., M. Fernández-Olmos, M. Ramírez-Alesón, and N. Utrero-González. 2020. "Characterisation of Technological Collaborations and Evolution in the Spanish Defence Industry." Defence and Peace Economics 1-20. doi:10.1080/10242694.2020.1799168.

Camilleri, M. 2020. "European Environment Policy for the Circular Economy: Implications for Business and Industry Stakeholders.” Sustainable Development 28 (6): 1804-1812. doi:10.1002/ sd.2113.

Carayannis, E., and D F. Campbell. 2012. "Editorial Preface to the First Volume of Journal of Innovation and Entrepreneurship." Journal of Innovation and Entrepreneurship 1 (1): 1-12. doi:10.1186/2192-5372-1-1. 
Carayannis, E., and D. Campbell. 2009. “Mode 3'and'Quadruple Helix’: Toward a 21st Century Fractal Innovation Ecosystem.” International Journal of Technology Management 46 (3-4): 201-234. doi:10.1504/IJTM.2009.023374.

Carayannis, E., and D. Campbell. 2010. "Triple Helix, Quadruple Helix and Quintuple Helix and How Do Knowledge, Innovation and the Environment Relate to Each Other? A Proposed Framework for A Trans-disciplinary Analysis of Sustainable Development and Social Ecology." International Journal of Social Ecology and Sustainable Development 1 (1): 41-69. doi:10.4018/ jsesd.2010010105.

Castillo-Montoya, M. 2016. "Preparing for Interview Research: The Interview Protocol Refinement Framework.” Qualitative Report 21 (5): 811-831.

CDP. 2019. “2018 CDP Revision”. European Defense Industry. Accessed 24 March 2021. Accessed March 24. https://eda.europa.eu/docs/default-source/eda-publications/eda-brochure-cdp

Chesbrough, H. 2003. Open Innovation: The New Imperative for Creating and Profiting from Technology. Boston, MA, USA: Harvard Business School Press.

Choi, B., and A. Pak. 2006. "Multidisciplinarity, Interdisciplinarity and Transdisciplinarity in Health Research, Services, Education and Policy: 1. Definitions, Objectives, and Evidence of Effectiveness." Clinical and Investigative Medicine. Medecine Clinique Et Experimentale 29 (6): 351-364.

Declaration of Helsinki. 2013. "Declaration of Helsinki: Medical Research Involving Human Subjects". World Medical Association. Accessed 16 March 2021. https://www.wma.net/whatwe-do/medical-ethics/declaration-of-helsinki/

DEFIS. 2021. "Defence Industry and Space". Directorate-General DEFIS. Accessed 19 March 2021. https://ec.europa.eu/info/departments/defence-industry-and-space_en

DGNDR. 2021a. "The Development of a European Defence Technological and Industrial Base (EDTIB).” Directorate-General for External Policies. Accessed March 14. https://www.dgrdn. gov.pt/dgrdn/a-dgrdn/missao.html

DGNDR. 2021b. “Missão.” Direção-Geral de Recursos da Defesa Nacional. Accessed March 14. https://www.dgrdn.gov.pt/dgrdn/a-dgrdn/missao.html

Dominese, G. 2020. "Dual Technologies Sectors Innovation and Growth Civil and Defence Industries in Europe versus US and China." Journal Transition Studies Review 27 (1): 3-46.

Drisko, J., and T. Maschi. 2016. Content Analysis. Pocket Guides to Social Work. New York, NY, USA: Oxford University Press.

Dzwigol, H., M. Dzwigol-Barosz, and A. Kwilinski. 2020. "Formation of Global Competitive Enterprise Environment Based on Industry 4.0 Concept." International Journal of Entrepreneurship 24 (1): 1-5.

EDA. 2021a. "Mission". European Defense Industry. Accessed March 1. https://eda.europa.eu/whowe-are/Missionandfunctions

EDA. 2021b. "Permanent Structured Cooperation (PESCO)". European Defense Industry. Accessed March 2. https://eda.europa.eu/what-we-do/EU-defence-initiatives/permanentstructured-cooperation-(PESCO)

EDA. 2021c. "Capability Development Plan". European Defense Industry. Accessed March 2. https://eda.europa.eu/what-we-do/all-activities/activities-search/capability-development-plan

EEAS. 2021a. "The Common Security and Defence Policy (CSDP)". EEAS Homepage. Accessed March 19. https://eeas.europa.eu/topics/common-security-and-defence-policy-csdp_en?page=3

EEAS. 2021b. "European External Action Service”. European Union. Accessed March 20. https:// europa.eu/european-union/about-eu/institutions-bodies/eeas_en

Etzkowitz, H., and L. Leydesdorff. 1995. "The Triple Helix-University-industry-government Relations: A Laboratory for Knowledge Based Economic Development.” EASST Review 14 (1): 14-19.

Etzkowitz, H., and L. Leydesdorff. 2000. “The Dynamics of Innovation: From National Systems and "Mode 2" to a Triple Helix of University-industry-government Relations." Research Policy 29 (2): 109-123. doi:10.1016/S0048-7333(99)00055-4.

EU Space Policy. 2021. "Defence Industry and Space". European Commission. Accessed March 19. https://ec.europa.eu/defence-industry-space/eu-defence-industry_en 
European Defence Agency. 2012. "European Armed Forces Go Green Factsheet.” Accessed March 15. http://www.eda.europa.eu/docs/documents/V3-

Go_green_Factsheet_150312_CS5_vert

European Parliament. 2020. "In-depth Analysis. The EU's Defence Technological and Industrial Base.” Report from the Directorate-General for External Policies. Accessed March 22. https:// www.europarl.europa.eu/RegData/etudes/IDAN/2020/603483/EXPO_IDA(2020)603483_EN. pdf

Evans, K., and A. Alderson. 2000. "Auxetic Materials: Functional Materials and Structures from Lateral Thinking!” Advanced Materials 12 (9): 617-628. doi:10.1002/(SICI)1521-4095(200005) 12:9<617::AID-ADMA617>3.0.CO;2-3.

Fangueiro, R., and S. Rana. 2019. Advanced Materials for Defense. Cham, Switzerland: Trans Tech Publications, Limited.

Fernandes, L., G. Rosa, L. Araújo, and J. Andrade. 2020. "The Triple Helix Approach in the Defence Industry: A Case Study at the Brazilian Army." World Review of Science, Technology and Sustainable Development 16 (1): 22-43. doi:10.1504/WRSTSD.2020.105584.

Fiott, D. 2014. "Reducing the Environmental Bootprint? Competition and Regulation in the Greening of Europe's Defense Sector.” Organization \& Environment 27 (3): 263-278. doi:10.1177/1086026614528807.

Galletta, A. 2013. Mastering the Semi-structured Interview and Beyond: From Research Design to Analysis and Publication. New York, USA: NYU press.

Gerring, J. 2006. Case Study Research: Principles and Practices. Cambridge, UK: Cambridge University Press.

Gibbs, G. 2018. Analysing Qualitative Data. 2nd ed. Thousand Oaks, California, USA: SAGE Publications.

Given, L. 2008. The SAGE Encyclopedia of Qualitative Research Methods. London, UK: SAGE Publications.

Guest, G., A. Bunce, and L. Johnson. 2006. "How Many Interviews are Enough? an Experiment with Data Saturation and Variability." Field Methods 18 (1): 59-82. doi:10.1177/ 1525822 X05279903.

Hennink, M. M., B. N. Kaiser, and V. C. Marconi. 2017. "Code Saturation versus Meaning Saturation: How Many Interviews are Enough?” Qualitative Health Research 27 (4): 591-608. doi:10.1177/1049732316665344.

idD. 2021. “A idD”. idD Portugal Defense. Accessed March 16. https://www.iddportugal.pt/a-idd/ Krippendorff, K. 2018. Content Analysis: An Introduction to Its Methodology. Thousand Oaks, California, USA: SAGE Publications.

Langlois, J., S. Ben Mahmoud-Jouini, and R. Servajean-Hilst 2020. "Secrecy in Open Innovation and Open Innovation in Secrecy." HEC Paris Research Paper No. MOSI-2020-1396. 10.2139/ ssrn.3724176.

Lawrence, M., H. Stemberger, A. Zolderdo, D. Struthers, and S. Cooke. 2015. "The Effects of Modern War and Military Activities on Biodiversity and the Environment." Environmental Reviews 23 (4): 443-460. doi:10.1139/er-2015-0039.

Lew, Y., and J. Park. 2020. "The Evolution of N-helix of the Regional Innovation System: Implications for Sustainability.” Sustainable Development. doi:10.1002/sd.2143.

Lolaki, A., M. Zarrebini, D. Mostofinejad, M. Shanbeh, and S. Abtahi. 2020. "Intensification of Auxetic Effect in High Stiffness Auxetic Yarns with Potential Application as the Reinforcing Element of Composite." Journal of Industrial Textiles 1528083720978918.

Lune, H., and B. Berg. 2017. Qualitative Research Methods for Social Sciences. MA, USA: Pearson Education Company.

Machlis, G., and T. Hanson. 2011. "Warfare Ecology.” In Warfare Ecology. NATO Science for Peace and Security Series C: Environmental Security, edited by Machlis, G., T. Hanson, Z. Špirić, and J McKendry. Dordrecht: Springer. 33-40 . doi:10.1007/978-94-007-1214-0_5.

Marler, T., and A. Moore. 2011. "Military Threats to Terrestrial Resources Not Restricted to Wartime: A Case Study from Guam." Journal of Environmental Science \& Engineering 5: 1198-1214. 
Marler, T. 2013. "Military Ecology More Fitting than Warfare Ecology." Environmental Conservation 40 (3): 207. doi:10.1017/S0376892913000179.

Marshall, B., P. Cardon, A. Poddar, and R. Fontenot. 2013. "Does Sample Size Matter in Qualitative Research? A Review of Qualitative Interviews in IS Research.” Journal of Computer Information Systems 54 (1): 11-22. doi:10.1080/08874417.2013.11645667.

Martín-Martín, A., M. Thelwall, E. Orduna-Malea, and E. López-Cózar. 2021. "Google Scholar, Microsoft Academic, Scopus, Dimensions, Web of Science, and OpenCitations' COCI: A Multidisciplinary Comparison of Coverage via Citations." Scientometrics 126 (1): 871-906. doi:10.1007/s11192-020-03690-4.

Merriam, S., and E. Tisfell. 2015. Qualitative Research: A Guide to Design and Implementation. MA, USA: John Wiley \& Sons.

Mills, A., G. Eurepos, and E. Wiebe. 2010. Encyclopedia of Case Study Research. Thousand Oaks, California, USA: SAGE Publications.

Moher, D., A. Liberati, J. Tetzlaff, and D. Altman, Prisma Group. 2009. "Preferred Reporting Items for Systematic Reviews and Meta-analyses: The PRISMA Statement.” PLoS Medicine 6 (7): e1000097.10.1371/journal.pmed.1000097.

Nádudvari, A., A. Etl, and N. Bereczky. 2020. "Quo Vadis, PESCO? an Analysis of Cooperative Networks and Capability Development Priorities.” Stratégiai Védelmi Kutató Központ (Elemzések)/center for Strategic and Defense Studies Analyses 15: 1-27.

Neuendorf, K., and A. Kumar. 2015. "Content Analysis". The International Encyclopedia of Political Communication, 1-10. Wiley Online Library. Accessed March 16 https://onlineli brary.wiley.com/doi/abs/10.1002/9781118541555.wbiepc065

Oliva, S., Á. Martínez-Sánchez, and F. Escribano-Bernal. 2019. “Towards a Contingent Approach to Firm Strategy on the Lowest Levels of the Hierarchy of the Defence Industry." Foresight 21 (5): 582-604. doi:10.1108/FS-11-2018-0094.

PESCO. 2020. “Projects”. PESCO Member States Driven. Accessed March 24. https://pesco.europa.eu/\#

Petticrew, M., and H. Roberts. 2008. Systematic Reviews in the Social Sciences: A Practical Guide. MA, USA: John Wiley \& Sons.

Randhawa, K., R. Wilden, and J. Hohberger. 2016. “A Bibliometric Review of Open Innovation: Setting A Research Agenda.” Journal of Product Innovation Management 33 (6): 750-772. doi:10.1111/jpim.12312.

Reis, J., P. Santo, and N. Melão. 2020. "Impact of Artificial Intelligence Research on Politics of the European Union Member States: The Case Study of Portugal." Sustainability 12 (17): 6708. doi:10.3390/su12176708.

Reis, J. 2021. "Politics, Power, and Influence: Defense Industries in the Post-Cold War." Social Sciences 10 (1): 10. doi:10.3390/socsci10010010.

Rogo, F., L. Cricelli, and M. Grimaldi. 2014. "Assessing the Performance of Open Innovation Practices: A Case Study of A Community of Innovation.” Technology in Society 38: 60-80. doi:10.1016/j.techsoc.2014.02.006.

Saunders, M., and K. Townsend. 2016. "Reporting and Justifying the Number of Interview Participants in Organisation and Workplace Research." British Journal of Management 27 (4): 836-852. doi:10.1111/1467-8551.12182.

Seawright, J. 2016. Multi-method Social Science: Combining Qualitative and Quantitative Tools. Cambridge, UK: Cambridge University Press.

Silva, M., and C. Olavo-Quandt. 2019. "Defense System, Industry and Academy: The Conceptual Model of Innovation of the Brazilian Army." Journal of Technology Management \& Innovation 14 (1): 53-62. doi:10.4067/S0718-27242019000100053.

Simões, P., A. Moreira, and C. Mendes Dias. 2020. "Portugal's Changing Defense Industry: Is the Triple Helix Model of Knowledge Society Replacing State Leadership Model?” Journal of Open Innovation: Technology, Market, and Complexity 6 (4): 183. doi:10.3390/joitmc6040183.

Steffens, F., F. Oliveira, and R. Fangueiro. 2021. "Energy Absorption from Composite Reinforced with High Performance Auxetic Textile Structure." Journal of Composite Materials 55 (7): 1003-1013. doi:10.1177/0021998320964552. 
Steinbock, D. 2014. “The Erosion of America's Defense Innovation.” American Foreign Policy Interests 36 (6): 366-374. doi:10.1080/10803920.2014.993251.

Sundler, A., E. Lindberg, C. Nilsson, and L. Palmér. 2019. "Qualitative Thematic Analysis Based on Descriptive Phenomenology.” Nursing Open 6 (3): 733-739. doi:10.1002/nop2.275.

Torgerson, C. 2003. Systematic Reviews. London, UK: Bloomsbury Publishing.

Tracy, S. 2019. Qualitative Research Methods: Collecting Evidence, Crafting Analysis, Communicating Impact. MA, USA: John Wiley \& Sons.

Tranfield, D., D. Denyer, and P. Smart. 2003. “Towards a Methodology for Developing Evidenceinformed Management Knowledge by Means of Systematic Review." British Journal of Management 14 (3): 207-222. doi:10.1111/1467-8551.00375.

Underhill, R. 2014. "Defense Applications of Auxetic Materials.” Advanced Materials 1 (1): 7-12.

Vaismoradi, M., H. Turunen, and T. Bondas. 2013. "Content Analysis and Thematic Analysis: Implications for Conducting a Qualitative Descriptive Study.” Nursing \& Health Sciences 15 (3): 398-405. doi:10.1111/nhs.12048.

Vilaça, Alexis. 2021. "AuxDefense Products”. Alexis Vilaça. Accessed 2 April 2021. Accessed April 2. https://alexisvilaca.com/work/auxdefense-products

Wang, Z., A. Zulifqar, and H. Hu. 2016. "Auxetic Composites in Aerospace Engineering. Sohel , Rana, and Raul , Fangueiro.” In Advanced Composite Materials for Aerospace Engineering, 213-240. Sawston, Cambridge, UK: Woodhead Publishing.

Wang, Z., and H. Hu. 2014. "Auxetic Materials and Their Potential Applications in Textiles." Textile Research Journal 84 (15): 1600-1611. doi:10.1177/0040517512449051.

Woolf, N., and C. Silver. 2017. Qualitative Analysis Using NVivo: The Five-level QDA ${ }^{\circledR}$ Method. New York, USA: Routledge.

Yin, R. 2018. Case Study Research and Applications: Design and Methods. 6th ed. Thousand Oaks, California, USA: SAGE Publications.

Yuan, C., S. Liu, Y. Yang, and Y. Shen. 2016. "On the Contribution of Defense Innovation to China's Economic Growth.” Defence and Peace Economics 27 (6): 820-837. doi:10.1080/ 10242694.2014.901644. 